\title{
Pulmonary function in preoperative, postoperative and post hospital discharge after heart surgery: controlled clinical study
}

\author{
Jully Wendy Soares ${ }^{1}$, Gabriela Xavier Santos ${ }^{2}$, Monica Beatriz Ferreira ${ }^{1}$, Bruno Bonfim Foresti ${ }^{1}$, Danillo
} Barbosa $^{3^{*}}$, Viviane Cristine Ferreira ${ }^{1}$.

${ }^{1}$ Centro Universitário do Sul de Minas Gerais - UnisMG, Varginha (MG), Brazil; ${ }^{2}$ Universidade Federal de Alfenas - UniFal, Alfenas (MG), Brazil; ${ }^{2}$ Universidade Estadual do Centro Oeste do Paraná - Unicentro, Guarapuava (PR), Brazil

\begin{abstract}
Background: Cardiac surgery may influence respiratory function at different times, such as before and after surgery, and after hospital discharge. Objective: Evaluate the respiratory functionality (respiratory muscle strength and peak expiratory flow-PEF) of pre, postoperative and post-hospital discharge of cardiac surgery patients at a Regional Hospital in the south of Minas Gerais. Methods: The sample consisted of 11 subjects: 6 women $(54.4 \%)$ and 5 men (45.46\%), with mean age of \pm 60 years. The mean height, weight and BMI were respectively: $\pm 1.61 \mathrm{~m}$, $\pm 71.08 \mathrm{~kg}$ and \pm 26.89 . Results: The values of the functional variables were lower than expected; men had the highest values of maximal inspiratory pressure (MIP), maximal expiratory pressure (MEP) and PEF at the 3 moments; there was correlation $r_{s}<1 p<0.01$ of PRE MIP and POS MIP; PRE MIP and POS MEP; third day MIP and PRE MIP; and POS MEP and PRE MEP. Conclusion: men had the highest values of respiratory functional variables. The analysis of the variables at the 3 moments showed that after hospital discharge most of them reduced their values. The post hospital discharge should be a concern of professionals assisting cardiac surgery patients.

Keywords: Heart Surgery; Respiratory Muscle Strength; Peak Expiratory Flow.
\end{abstract}

\section{BACKGROUND}

Cardiac surgery (CS) is a highly complex procedure that causes changes in several physiological mechanisms and great organic and psychic stress to the subject ${ }^{(1)}$. Approximately 350 cardiac surgeries / 1,000,000 inhabitant / year are performed in Brazil, including pacemakers and defibrillators $^{(2)}$. CS may cause decreased lung volume and capacity, as well as decreased respiratory muscle strength, which contributes to the increased incidence of respiratory complications that are the major cause of postoperative CS morbidity ${ }^{(3)}$. Patients undergoing cardiac surgery undergo a series of preoperative examinations and tests to avoid possible complications ${ }^{(4)}$.

Some of these tests performed preoperatively are manovacuometry and peak expiratory flow (PEF), low-cost tests that minimize the risk of respiratory function impairment ${ }^{(5)}$. The measurement of respiratory muscle strength allows the diagnosis of respiratory failure in several pathologies, in which occur changes in the contractile strength of these muscles, and depending on the intensity and quantification can be classified as respiratory muscle weakness, fatigue or failure ${ }^{(6)}$. There is evidence that patients who do not have high preoperative maximal inspiratory pressure(MIP) and maximal expiratory pressure (MEP) have a higher risk of developing postoperative pulmonary complications, and some authors have even suggested the inclusion of MEP on a risk factor scale for patients undergoing cardiac surgery ${ }^{(7)}$.

Usually the postoperative period comes with pulmonary complications which is a condition that may be caused by some conditions arising from cardiac surgery such as: anesthetic procedure, surgical incision, cardiopulmonary bypass (CPB), ischemia time, intensity of surgical manipulation and number of pleural drains, so preoperative physiotherapy work becomes indispensable ${ }^{(8)}$. In this context, the research aimed to follow cardiac surgery patients from pre, post and hospital discharge through pulmonary functional assessment.

\section{METHODS \\ Study Ethics}

This study was approved by the Ethics Committee of the Centro Universitário do Sul de Minas - Unis/ MG through the "Plataforma Brasil" with number 1.881.079 and CAAE 63229416.1 .0000 .511 , following the rules established by CNS Resolution 466/12, maintaining anonymity and total privacy of the participants involved.

\section{Type of Study}

It is a clinical, controlled, observational, qualitative and prospective cohort study. 


\section{METHODS}

\section{Characterization of the place of study}

It was performed in an intensive care unit (ICU) in the cardiology sector of a referral hospital in southern Minas Gerais.

\section{Sample Characterization}

Volunteers were invited to participate voluntarily by signing the informed consent form. The sample consisted of 11 volunteers $(n=6$ females and $n=5$ males) aged \pm 18 to \pm 80 years. The mean height, weight and BMl were respectively: $\pm 1.61 \mathrm{~m}$, $\pm 71.08 \mathrm{~kg}$ and \pm 26.89 .

\section{Inclusion criteria}

Accept to participate in the research and sign the informed consent form; have a level of awareness in alertness and cooperative; being in the age group of 18 to 80 years old; and being hemodynamically stable according to the exams and daily evolutions described in the medical records.

\section{Exclusion criteria}

Present hemodynamic instability and be under medication (sedation/anesthesia) and do not sign the informed consent form.

\section{Respiratory Muscle Strength Assessment}

Respiratory muscle strength was assessed by the manovacuometer (Comercial Médica, model M120) with a scale of $\pm 120 \mathrm{cmH} 2 \mathrm{O}$. This is a classic instrument for assessing respiratory muscle strength at the mouth level. Measurements were made with subjects seated in a chair using a mouth and a nose clip firmly coupled between the lips throughout the procedure to prevent ventilatory escape. First two maneuvers were performed for learning. The evaluation was considered complete when the subject was able to perform three acceptable measurements and two reproducible measurements.

As acceptability criteria were standardized the maneuvers without air leakage with sustained pressure for at least 2 seconds and reproducibility in which the variation of values was equal to or less than $10 \%$ between the measurements, and the last value cannot be higher than the others. The MIP was determined by the patient exhaling at residual volume (RV) level followed by an inspiration at total lung capacity (TLC). The MEP was measured with the patient performing an inspiration at TLC and then exhaling all air at the RV level. One-minute interval between measures to prevent fatigue was stipulated, and the highest value between reproducible maneuvers was selected for analysis.
The reference values were calculated according ${ }^{(9)}$ to the current references. The equation for calculating MIP, regarding age and gender, for males is $-1.24 \times$ age +232.37 and females is $-0.46 \times$ age +74.25 . The equation for o calculating MEP for males is $1.26 \times$ age +183.31 and females is $-0.68 \times$ age + 119.35 .

\section{Peak Expiratory Flow Assessment}

It was used the peak expiratory flow meter (Healthscan Products Inc.). It is a small portable device made of clear plastic material, containing a graduated measuring system that evaluates the force and velocity of air exiting the lungs in L/min. To obtain maximum peak expiratory flow measurements, the subject must forcefully exhale through the mouthpiece after maximum inspiration.

During data collection the researcher holds the device vertically, being careful to not block the air exit with the fingers and then the patient placed his/her mouth firmly around the plastic mouthpiece, making sure that no air escapes to not interfere with measurements, and blows hard and as fast as possible. At least 3 maximum peak expiratory flow measurements were performed, provided that the last one was not higher than the others and that there were no differences between the measurements greater than 5\%. The largest measure was used for statistical analysis.

\section{Data analysis}

Results were presented as mean and standard deviation $(M \pm S D)$. Respiratory muscle strength consistency and peak expiratory flow were analyzed using SPSS (Statistical Package for the Social Sciences). For continuous variables with normal distribution, the nonparametric Spearman test was used for paired samples and for correlation. The significance level adopted was $p<0.01$.

\section{RESULTS}

The sample consisted of 11 volunteers: 6 $(54.4 \%)$ females and $5(45.46 \%)$ males. The average age was \pm 60 years: females \pm 63 years and males \pm 57.7 years. The average height variable was $\pm 1.61 \mathrm{~m}$, being $\pm 1.57 \mathrm{~m}$ for females and $\pm 1.65 \mathrm{~m}$ for males. The average weight of the volunteers was $\pm 71.08 \mathrm{~kg}$, being $\pm 62.58 \mathrm{~kg}$ for females and $\pm 78.16 \mathrm{~kg}$ for males. The body mass index (BMI) of the sample was \pm 26.89 , being \pm 25.39 for females and \pm 28.48 for males. Regarding the presence of comorbidities, the majority of the sample had hypertension 2 (18.19\%) (Table 1). 
Table 1. Distribution of participants according to comorbidities

\begin{tabular}{llc}
\hline Variables & $\mathrm{n}$ & $\%$ \\
\hline Systolic Arterial Hypertension (SAH) & 2 & 18.19 \\
SAH/ASMA & 1 & 9.09 \\
Diabetes Mellitus type I (DMI) and Obesity & 1 & 9.09 \\
SAH and hypothyroidism & 1 & 9.09 \\
SAH/DMI and Kidney disease & 1 & 9.09 \\
SAH/ Chronic obstructive pulmonary disease & 1 & 9.09 \\
COPD/Diabetes & 1 & 9.09 \\
SAH/Obesity & 1 & 9.09 \\
SAH/Asthma/Heart disease & 1 & 9.09 \\
SAH/COPD/Ethylist/Varicose veins & 1 & 9.09 \\
Total & 11 & 100 \\
\hline
\end{tabular}

The research investigated smoking in which it can verify that 7 (63.54\%) never smoked; $3(27.27 \%)$ are smokers and 1 (9.09\%) are former smoker. Physical inactivity and physical activity were also investigated and showed that $11(100 \%)$ volunteers are sedentary. Volunteers were investigated on clinical diagnosis and the predominance was $3(27.28 \%)$ with coronary insufficiency. (Table 2.0). In table 3, it can be observed that the mean time of extracorporeal circulation (ECC) was 46.65 ( \pm 15.89), being $49.8( \pm 20.4)$ for males and $43.23( \pm 7.4)$ for females.

Table 2. Distribution of participants according to diagnostic variable

\begin{tabular}{lcc}
\hline Variables & $\mathrm{n}$ & $\%$ \\
\hline Clinical diagnosis & 3 & 27.28 \\
Coronary insufficiency (Cl) & 2 & 18.18 \\
Interatrial Communication & 2 & 18.18 \\
Coronary insufficiency/Congestive Heart Failure & 1 & 9.09 \\
Aortic stenosis & 1 & 9.09 \\
Aortic Valve Disease & 1 & 9.09 \\
Aortic Insufficiency & 1 & 9.09 \\
Acute myocardial infarction & 11 & 100 \\
Total & & \\
\hline
\end{tabular}


Table 3. Distribution of the volunteers according to the time of extra-corporeal circulation variable

Variable

Male $\quad$ Female Total

\begin{tabular}{lllllll}
\hline Time of ECC extra-corporeal & $49.8 \pm$ & 20.4 & $43.23 \pm$ & 7.4 & $46.65 \pm$ & 15.89
\end{tabular}

circulation (minutes)

Regarding the type of surgery, there was a predominance in females as follows: 2 (18.18\%) myocardial revascularization surgery (MRS); 2 (18.18\%) aortic valve replacement (AVR); 1 (9.09\%) AVR and MRS and 1 (9.09\%) IC. In males the predominance was: 2 (18,18\%) AVR and reoperation; 1 (9,09\%) mitral VR and AVR and 1
$(9,09 \%)$ MRS. The functional tests selected in the research were manovacuometry and peak expiratory flow evaluated at three moments: preoperative; 3rd postoperative day and hospital discharge. Table 4 presents the values for the 3 moments.

Table 4. Distribution of participants according manovacuometry and peak expiratory flow

\begin{tabular}{llll}
\hline Variables & Male & Female & Total \\
\end{tabular}

Preoperative

$\begin{array}{lccc}\text { MIP } & -72 \pm 34.29 & -56.66 \pm 35.74 & -63.63 \pm 35.74 \\ \text { MEP } & 42 \pm 12.2 & 31.66 \pm 14.62 & 36.36 \pm 16.16 \\ \text { PEF } & 304 \pm 87.04 \pm & 193.3 \pm 62.63 & 242.72 \pm 92.25\end{array}$

3rd postoperative day

$\begin{array}{lccr}\text { MIP } & -72 \pm 31.24 & 46.66 \pm 24.94 & -58.18 \pm 30.69 \\ \text { MEP } & 52 \pm 4 & 26.66 \pm 12.47 & 38.18 \pm 15.85 \\ \text { PEF } & 168 \pm 56.35 & 166.6 \pm 47.84 & 167.27 \pm 51.88\end{array}$

Hospital discharge

$\begin{array}{lrrr}\text { MIP } & -70 \pm 26.83 & 53.33 \pm 20.55 & -60.90 \pm 25.02 \\ \text { MEP } & 50 \pm 18.02 & 31.66 \pm 15.72 & 40 \pm 19.54 \\ \text { PEF } & 230 \pm 100.12 & 176.6 \pm 42.69 & 200.90 \pm 73.41\end{array}$

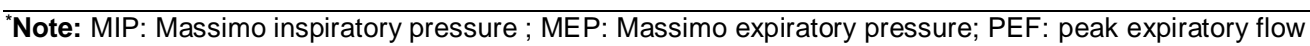


Upon the expected values: male with MIP (201 $\left.\mathrm{cmH}_{2} \mathrm{O}\right)$, MEP $\left(212 \mathrm{cmH}_{2} 0\right)$ and PEF $(523-526 \mathrm{~L} / \mathrm{s})$ and female MIP $\left(141,4 \mathrm{cmH}_{2} 0\right)$, MEP $\left(154 \mathrm{cmH}_{2} 0\right)$ and PEF (371 - $383 \mathrm{~L} / \mathrm{s})$. The sample obtained values below expectations. Another observed data was that in the 3 moments of the collection males presented higher values of MIP, MEP and PEF, however on the 3rd postoperative day the PEF values showed a minimal superiority compare to females. Checking the MIP data, males in the preoperative period $(-72 \mathrm{cmH} 20( \pm 34.29)$ and postoperative $(-72 \mathrm{cmH} 20( \pm 31.24)$ maintained the mean, but in the post-hospital discharge $(-70 \mathrm{cmH} 20$ $( \pm 26.28)$ the inspiratory force decreased. Females in the preoperative $\left(-56.66 \mathrm{cmH}_{2} \mathrm{O}( \pm 35.74)\right.$ showed higher value regarding the postoperative $\left(-46 \mathrm{cmH}_{2} \mathrm{O}\right.$ $( \pm 24.94)$ and the post-hospital discharge $(-53.33$ $\mathrm{cmH}_{2} \mathrm{O}( \pm 20.55)$.

The data of MEP for males were in the preoperative of $42 \mathrm{cmH}_{2} \mathrm{O}( \pm 12.2)$ and in the posthospital discharge of $50 \mathrm{cmH}_{2} \mathrm{O}( \pm 18.02)$ and increased in the 3 rd postoperative day $\left(52 \mathrm{cmH}_{2} \mathrm{O}\right.$ $( \pm 14.01)$. Regarding the females, the preoperative was $31.66 \mathrm{cmH}_{2} \mathrm{O}( \pm 14.62)$ and the post-hospital discharge was $31.66 \mathrm{cmH}_{2} \mathrm{O}( \pm 15.72)$ maintaining the values and decreased in the 3rd postoperative day $\left(26.66 \mathrm{cmH}_{2} \mathrm{O}( \pm 142.47)\right.$. According to PEF, males had the following data: preoperative 302 ( \pm 87.04$)$; 3rd postoperative day $168( \pm 56.35)$ and post-hospital discharge $230( \pm 100.12)$, then the best performance was preoperatively. And females had similar values: preoperative 193.33 ( \pm 62.63$)$; 3rd postoperative day $166.66( \pm 47.84)$ and post-hospital discharge $176.66( \pm 42.69)$, i.e., the higher value was in the preoperative.

Table 5 describes the analysis of Spearman correlation $\left(r_{s}\right)$ with $p 0.01$ significance related to the variables of the preoperative phase. There was correlation with the following variables: $\mathrm{BMI}$ with the weight $\left(r_{s}=0.768\right) p$ 0.006; Pre MIP and Post MIP $\left(r_{s}=0.781\right) p$ 0.005; Pre MIP and Post MEP $\left(r_{s}=\right.$ $0.876) p 0.000$ and Pre MEP and Post MIP $\left(r_{s}=\right.$ $0.885) p 0.000$. It can be understood that the sample obtained low BMI because the average weight is low. Preoperative inspiratory strength was low, which led to remain low after hospital discharge. The low inspiratory force contributed to keep the postdischarge expiratory force reduced. Preoperative expiratory muscle strength contributed to the decrease in postoperative inspiratory strength.

Table 5. Correlation of preoperative variables according to Spearman $\left(\mathrm{r}_{\mathrm{s}}\right)$ with $p 0.01$ of significance

\begin{tabular}{lccc} 
Variables & & $r_{s<1}$ & $P$ \\
\hline BMI & Weight & 0.764 & 0.006 \\
Pre MIP & Post MIP & 0.781 & 0.005 \\
Pre MIP & Post MEP & 0.876 & 0.000 \\
Pre MEP & Post MIP & 0.885 & 0.000
\end{tabular}

${ }^{*}$ Note: MIP: Massimo inspiratory pressure; MEP: Massimo expiratory pressure; BMI: Body mass index. The variables were correlated in parallel for the performance of the non-parametric Spearman test $r s<1$, being $p<0.01$.

The Spearman correlation $\left(\mathrm{r}_{\mathrm{s}}\right)$ analysis with $p$ 0.01 of significance with the variables of the third postoperative day showed correlation with the following variables: MIP of the third postoperative day with the Pre MIP $\left(r_{s}=0.796\right) p 0.003$ and MEP of the third postoperative day with the MIP of the third postoperative day $\left(r_{s}=0.824\right) p 0.002$, (Table $6)$.

Table 6. Correlation of 3rd postoperative day variables according to Spearman $\left(r_{s}\right)$ with $p 0.01$ of significance

\begin{tabular}{|c|c|c|c|}
\hline Variables & & $r_{s<1}$ & $P$ \\
\hline MIP $3^{\text {rd }}$ day & Pre MIP & 0.796 & 0.003 \\
\hline MEP $3^{\text {rd }}$ day & MIP $3^{\text {rd }}$ day & 0.824 & 0.002 \\
\hline
\end{tabular}

${ }^{\overline{ }}$ Note: MIP: Massimo inspiratory pressure; MEP: Massimo expiratory pressure. The variables were correlated in parallel to the realization of the non-parametric Spearman test $r \mathrm{~s}<1$, being $\mathrm{p}<0.01$. 
Thus, the inspiratory force on the 3rd postoperative day is due to the reduced inspiratory force. The expiratory force of the 3rd day was decreased as the inspiratory force of the 3rd day. According to the table 7, the Spearman correlation $\left(r_{s}\right)$ analysis with $p 0.01$ of significance with the variables post-hospital discharge showed correlation with the Post MEP with Pre MEP $\left(r_{s}=\right.$ 0.767) $p 0.006$, i.e., evidences that the reduced post-hospital discharge expiratory force accompanied the low preoperative expiratory force.

Table 7. Correlation of post-hospital discharge day variables according to Spearman $\left(\mathrm{r}_{\mathrm{s}}\right)$ with $p 0.01$ of significance

\section{Variables}

$r_{s<1}$

$P$

Post MEP

Pre MEP

0.767

0.006

${ }^{\star}$ Note: MEP: Massimo expiratory pressure. The variables were correlated in parallel to the realization of the non-parametric Spearman test $r \mathrm{~s}$ $<1$, being $\mathrm{p}<0.01$.

\section{DISCUSSION}

The research verified that the sample obtained values below the expected before the functional variables according to gender: males with MIP -72 ($201 \mathrm{cmH}_{2} \mathrm{O}$ expected), MEP 42 (212 $\mathrm{cmH}_{2} \mathrm{O}$ expected) and PEF 302 (523-526 L/s expected) and females with MIP -56.66 ( $-141.4 \mathrm{cmH}_{2} \mathrm{O}$ expected), MEP 31.66 (154 $\mathrm{cmH}_{2} \mathrm{O}$ expected) and PEF 193.33 (371-383 L/s expected), this fact may have occurred because the sample consisted mostly of women. This question was confirmed in a study ${ }^{(7)}$ that had 2 groups: HR (high risk) and LR (low risk), in which the HR group was composed by $75 \%$ females, thus, the HR group presented MIP values $17.7 \%$ below the predicted while the LR group, in which most of them were males, showed a $14.1 \%$ increase when compared to the reference values, and regarding MEP in the HR group, the values found were $8.2 \%$ lower while in the LR group these values were increased by $81.2 \%$ of the predicted values for age and gender.

Regarding the reduction of the PEF variable, a study ${ }^{(10)}$ that had two groups, which control group (CO) consisted of 15 subjects (9 were women), presented a significant decrease in peak expiratory flow on the first postoperative day, maintaining low values at the time of discharge, in the preoperative of $238.32 \pm 156.51 \mathrm{l} / \mathrm{mim}$, in the first postoperative day of $134.64 \pm 80.20 \mathrm{l} / \mathrm{mim}$ and in the last hospitalization day of $157.14 \pm 102.29 \mathrm{l} / \mathrm{mim}$.

These differences in the values of maximal respiratory pressures and flow between the genders may be related to the unequal amount of lean mass, since males have higher amounts of muscle mass and, consequently, more strength than females ${ }^{(11)}$. Males had higher values of MIP, MEP and PEF in the 3 moments of data measurement compared to women. However, analyzing each moment, men reduced MIP in the post-hospital discharge (-70 $\mathrm{cmH}_{2} \mathrm{O}$ ), increased in the 3rd postoperative day the MEP $\left(52 \mathrm{cmH}_{2} \mathrm{O}\right)$ and PEF was higher preoperatively (302 L/s). Simões et al. (2007) found significantly lower values $(p<0.01)$ in all subgroups of females from both MIP and MEP compared to males of the same age group (40 to 49 years, 50 to 59,60 to 69 , 70 to 79,80 to 89 years).

Other research data showed that males in the hospital discharge reduced MIP. Studies ${ }^{(3,12)}$ suggest that the fact that the patient is not assisted by the physiotherapist may contribute to this reduction. Another study ${ }^{(13)}$ pointed out that $96 \%$ of the sample, which was composed of males, reported that the incidence of tiredness, sleep pattern disorders and appetite change were reported at a high rate in the first 3 weeks after hospital discharge. These data may be directly linked to reduced respiratory muscle strength.

Respiratory and peripheral muscle strength are fundamental for health, for maintaining good functional capacity and for achieving a satisfactory quality of life. Patients with myocardial infarction, were physically ill-conditioned, unable to return to their domestic, social and professional activities when discharged from hospital, thus, it became evident that these patients need a therapeutic approach throughout the period of hospitalization and after hospital discharge ${ }^{(14)}$. On the other hand, women presented higher value of Pre MIP (-56.66 $\mathrm{cmH}_{2} 0$ ), decreased the MEP in the $3^{\text {rd }}$ postoperative day $\left(26.66 \mathrm{cmH}_{2} \mathrm{O}\right)$ different from the males, and had PEF higher in the Pre $(193.33 \mathrm{~L} / \mathrm{s})$ as males. 
The reduction in MEP values of women in the 3 rd postoperative day was observed in this study ${ }^{(3)}$. This statistically significant reduction $(p<0.05)$ in the MIP and MEP values in the POI, 3rd and 5th postoperative day in females when compared to the preoperative, explains that it may be a consequence of the non-restoration of respiratory muscle strength after surgery. Another explanation is through the study by Santos et al. (2010) in which the researcher explains that may be due to the lack of preparation of these muscles preoperatively, and the MEP was decreased in all periods when compared to the preoperative $^{(3)}$.

\section{CONCLUSION}

It was concluded that men presented the highest values of respiratory functional variables, although the reference values were not reached. The analysis of the variables at the 3 moments showed that after hospital discharge most of them reduced their values. The post hospital discharge should be a concern of professionals assisting cardiac surgery patients.

Authors' contributions: JWS and GXS: responsible for the project design, organization of articles for reading, writing the introduction, methodology and discussion. MBF, BBF, VCF: responsible for writing all sessions, phone calls to patients and data collection. DB: responsible for reviewing the entire text and statistical analysis.

Financial support: The authors declare that there are no Nonfinancial competing interests

Conflict of interest: The authors declare that there was no conflict of interests.

\section{REFERENCES}

1. Moura RS, Lima VP, Albuquerque WDM, Costa VC, Barreto DML, Cavalcanti RC. Autobiografia após as cirurgias de revascularização do miocárdica: História de vida na UTI cardíaca. Rev. de Enfermagem do centro oeste mineiro. 2017;7(1):01-10.

2. Carneiro RCM, Vasconcelos TB, Barros GG, Câmara TMS, Macena RHM, Bastos VPD. Estudo da força muscular respiratória em pacientes submetidos á cirurgia cardíaca em um hospital na cidade de Fortaleza/CE. UNOPAR Cient Ciênc Biol Saúde. 2013;15(4):265-271.

3. Dallazen F, Steinke GV, Vargas MO, Cruz DT, Lorenzoni JCW, Winkelmann ER. Avaliação no pós-operatório de cirurgia cardíaca de indivíduos que realizaram terapia com incentivador respiratório a fluxo. Rev. Contexto e Saúde. 2011;10(20):765-770.
4. Laizo A, Degaldo EF, Rocha GM. Complicações que aumentam o tempo de permanência na unidade de terapia intensiva na cirurgia cardíaca. Rev. Bras. Cir. Cardiovasc. 2010;25(2):166-171.

5. Medeiros AIC, Oliveira AS, Costa SKA et al. Avaliação da função pulmonar, força muscular respiratória e qualidade de vida no préoperatório de cirurgia cardíaca. Rev Fisioter S Fun. Fortaleza. 2016;5(2):14-22.

6. Romani JCP, Miara N, Carradore MJK. Avaliação clinica da função dos músculos respiratórios em adultos: Revisão de literatura. Caderno escola de saúde. 2013;11(1):1-19.

7. Guedes GP, Barbosa YRA, Holanda G. Correlação entre força muscular respiratória e tempo de internação pós-operatório. Rev. Fisioterapia Mov. 2009;22(4):605-614.

8. Chiapinotto $S$, Winkelmann ER. Incidência da dor pós-operatória em cirurgia cardíaca: uma revisão de literatura. XXI Jornada de Pesquisa. 2016.

9. Costa D, Gonçalves HA, Lima LP, Ike D, Cancelliero KM, Montebelo MIL. Novos valores de referência para pressões respiratórias máximas na população brasileira. J. bras. pneumol. 2010;36(3):1-9.

10. Barros GF, Santos CS, Granado FB, Costa PT, Límaco RP, Gardenghi G. Treinamento muscular respiratório na revascularização do miocárdio. Rev. Bras. Cir Cardiovasc. 2010;25(4):483-490.

11. Simões RP, Auad MA, Dionisio J, Mazzonetto $M$. Influência da idade e do sexo na força muscular respiratória. Fisioterapia e Pesquisa. 2007;14(1):36-41.

12. Dias CM, Vieira RO, Oliveira JF, Lopes AJ, Menezes SLS, Guimarães FS. Três protocolos fisioterapêuticos: Efeitos sobre volumes pulmonares após cirurgia cardíaca. J Bras Pneumol. 2010;37(1):54-60.

13. Dantas RAS, Aguillar OM. Problemas da recuperação de pacientes submetidos á cirurgia cardíaca de revascularização do miocárdio: o acompanhamento pelo enfermeiro durante 0 primeiro mês após a alta hospitalar. Rev. Latino Enf. 2001;9(6):31-36.

14. Diretrizes de Reabilitação Cardíaca. Arquivos Brasileiros de Cardiologia. 2005;84(5):431- 440. 